Contoyiannis, P.A., Draginis, E., Adamopoulos, D.A. \& Triantafyllou, G. (1975) Levodopa in coma due to fulminant hepatitis. British Medical Journal, 1, 272.

FISCHER, J.E. \& BALDESSARINI, R.J. (1971) False neurotransmitters and hepatic failure. Lancet, ii, 75.

FISCHER, J.E. \& JAMES, J.H. (1971) Medical news. Levodopa arouses patients from hepatic coma. Journal of the American Medical Association, 218, 1127.

FisCHER, J.E. \& JAMES, J.H. (1972) Treatment of hepatic coma and hepatorenal syndrome. Mechanism of action of L-dopa and aramine. American Journal of Surgery, 123, 222.

Gazzard, B.G., Portmann, B., Weston, M.J., Langley, P.G., Murray-Lyon, I.M., Dunlop, E.H., Flax, H., Mellon, P.J., Record, C.O., Ward, M.B. \& Williams, R. (1974) Charcoal haemoperfusion in the treatment of fulminant hepatic failure. Lancet, i, 1301.

LANZINGER, G. \& KoMmERELL, B. (1974) Levodopa-therapie beim hepatischen Koma. Deutsche medizinische Wochenschrift, 99, 700.

LUNZER, M. (1975) Encephalopathy in liver disease. British Journal of Hospital Medicine, 14, 33.

Lunzer, M., James, I.M., Weinman, J. \& Sherlock, S. (1974) Treatment of chronic hepatic encephalopathy with levodopa. Gut, 15, 555.

Parkes, J.E., Sharpstone, P. \& Williams, R. (1970) Levodopa in hepatic coma. Lancet, ii, 1341.

Sarrazin, A., Emerit, J., Oliver, L., Rebelo, F. \& Bousquet, O. (1971) Traitement de coma hépatique par la L-dopa. Presse Médicale, 79, 2226.

Stefanini, M. \& Hetherington, E.N. (1972) Levodopa in hepatic failure. Journal of the American Medical Association, 220, 1247.

Weiss, A., Pitman, E.R. \& Javdan, P. (1974) Arousal response in hepatic encephalopathy with L-dopa. American Journal of Gastroenterology, 62, 497.

\title{
Cardiac tamponade and acute renal failure following Salmonella agona pericarditis
}

\author{
JOHN WEBSTER \\ M.R.C.P.
}

\author{
NEIL EDWARD* \\ M.R.C.P. \\ JEFFREY PETERSEN* \\ M.R.C.P.
}

\section{Department of Therapeutics and Clinical Pharmacology, University of Aberdeen, and * Medical Renal Unit, Aberdeen Royal Infirmary}

\section{Summary}

A 19-year-old female presented with cardiac tamponade complicated by acute renal failure. Salmonella agona was cultured from pericardial aspirate after repeated pericardiocentesis in several sites. Treatment with ampicillin and intermittent haemodialysis led to complete recovery.

\section{Introduction}

Systemic complications of Salmonella infection are well described and are usually the result of bacteraemia (Christie, 1974). Pericarditis associated with typhoid fever and other invasive Salmonella spp. is uncommon although recognized for many years (Levin and Hosier, 1961) and in a few cases bacilli have been cultured from pericardial aspirate. Spontaneous cure has been described (Cohen, Fink and Gray, 1936) but death has occurred despite intensive antimicrobial therapy (Bird, 1969).

Correspondence: Dr John Webster, Department of Therapeutics and Clinical Pharmacology, University of Aberdeen Medical Buildings, Foresterhill, Aberdeen AB9 2ZD.

\section{Case report}

A 19-year-old female was admitted as an emergency with a 3-day history of malaise, anorexia and continuous substernal pain followed by rapid deterioration over $12 \mathrm{hr}$ with sweating, increasing breathlessness, tachycardia and hypotension. Before this she had been in excellent health except during a holiday in Benidorm, Spain, 6 weeks previously when she had had diarrhoea for 2 weeks.

On admission she was lucid and had an oral temperature of $38^{\circ} \mathrm{C}$. Examination showed orthopnoea, central cyanosis, unrecordable blood pressure, pulse of $140 / \mathrm{min}$ with a gallop rhythm and dullness to percussion with diminished breath sounds at her right base.

Chest X-ray showed cardiac enlargement, bilateral pulmonary congestion and early consolidation in the right lower zone. Electrocardiography showed sinus tachycardia and changes characteristic of acute pericarditis. Total white cell count was $17000 / \mathrm{mm}^{3}$ with a polymorph leucocytosis of $93 \%$. Serum biochemistry showed sodium $129 \mathrm{mmol} / \mathrm{l}$; potassium $6.0 \mathrm{mmol} / \mathrm{l}$; bicarbonate $14 \mathrm{mmol} / \mathrm{l}$; urea 12.7 
$\mathrm{mmol} / \mathrm{l}$; bilirubin $37 \mathrm{mmol} / \mathrm{l}$; alkaline phosphatase $51 \cdot 1$ i.u./l; aspartate amino transferase $>1000$ i.u./l.

Cardiac tamponade was suspected but initial attempts at pericardiocentesis in the fifth intercostal space yielded only $2 \mathrm{ml}$ of blood-stained fluid. The most likely diagnosis was thought to be biventricular failure due to infective myopericarditis and the patient was given digoxin, frusemide, hydrocortisone, gentamicin, cloxacillin and benzylpenicillin. The hyperkalaemia was treated with insulin, glucose and sodium polystyrene sulphonate. However, over the next $4 \mathrm{hr}$ there was further deterioration, the neck veins became distended, the heart sounds less distinct and the liver larger and more tender.

The diagnosis was reconsidered and a further pericardiocentesis in the fourth intercostal space yielded $250 \mathrm{ml}$ of turbid yellow fluid. Within a few minutes there was a dramatic improvement, signs of cardiac tamponade regressed and the blood pressure became recordable. A further $250 \mathrm{ml}$ of turbid pericardial fluid was aspirated $18 \mathrm{hr}$ later after which a loud pericardial rub became audible. Culture of the pericardial aspirate yielded profuse $S$. agona although cultures of blood, urine and stool remained negative throughout. Antibiotic therapy was changed to intramuscular ampicillin $4 \mathrm{~g}$ daily for 6 days, followed by oral ampicillin $2 \mathrm{~g}$ daily for a further 5 days.

Despite the restoration of normal blood pressure, the patient remained anuric and her blood urea rose to $50.5 \mathrm{mmol} / \mathrm{l} 4$ days after admission. Intermittent haemodialysis was then undertaken for a total of $47 \mathrm{hr}$ over the next 7 days when she remained anuric. She was severely oliguric for a further 7 days but 4 weeks after admission her renal function had returned to normal.

At review 2 months later complete recovery of renal and cardiac function was maintained, chest Xray and electrocardiogram were normal and there was no evidence of persisting Salmonella infection.

\section{Discussion}

Pericarditis is an uncommon complication of Salmonella infection and is most commonly associated with typhoid fever although a number of other Salmonella spp. have caused clinical pericarditis (Levin and Hosier, 1961). To the authors' knowledge, this is the first reported case of acute pericarditis due to $S$. agona.

Although the authors were unable to prove that their patient acquired the $S$. agona in Benidorm, this seems very likely and underlines the importance of considering unusual infections in patients who become ill after foreign travel.

Viruses are the commonest identifiable cause of acute pericarditis but early detection of the less frequent bacterial causes is of great therapeutic importance (Fowler and Manitsas, 1973). A very high polymorph leucocytosis was a feature of the present patient but this can occur non-specifically after any form of myocardial damage and is commonly seen in acute viral pericarditis (Gardiner and Short, 1973). If purulent pericarditis is suspected blood culture and pericardiocentesis are the most important investigations.

Chloramphenicol may still be the drug of first choice in grave Salmonella infections and its efficacy is not in doubt. However, ampicillin was chosen on the evidence of bacteriological sensitivity reports and in the belief that it carried less risk of adding drug toxicity to an already complicated clinical situation. It is likely that the initial empirical gentamicin therapy also contributed to the favourable response.

The differentiation of cardiac tamponade from acute biventricular cardiac failure and from rapidly progressive constrictive pericarditis can be difficult, as in this case. Pulsus paradoxicus suggests tamponade but was absent in the patient; the blood pressure being unrecordable until relief of the tamponade. Investigations such as fluoroscopy, radioisotope scanning or cardiac catheterization are not always appropriate in the ill patient, and echocardiography, although relatively easy to perform, is still not available at many peripheral hospitals. Pericardiocentesis is not without risk but if cardiac tamponade is suspected should be performed and repeated at different sites if necessary.

\section{Acknowledgment}

We wish to thank Dr C. D. Needham, Dr J. K. Finlayson and Dr M. MacLeod for permission to report this case.

\section{References}

BIRD, T. (1969) Salmonella typhimurium pericarditis. British Heart Journal, 31, 659.

Christie, A.B. (1974) Infectious Diseases: Epidemiology and Clinical Practice, 2nd edn. Churchill Livingstone.

CoHen, L., FInk, H. \& Gray, I. (1936) Salmonella suipestifer bacteraemia. Journal of the American Medical Association, $107,331$.

Fowler, N.O. \& Manitsas, G.T. (1973) Infectious pericarditis. Progress in Cardiovascular Diseases, 16, 323.

GaRdiner, A.J.S. \& SHORT, D. (1973) Four faces of acute myopericarditis. British Heart Journal, 35, 433.

LEVIN, H.S. \& Hosier, D.M. (1961) Salmonella pericarditis: report of a case and review of the literature. Annals of Internal Medicine, 55, 817. 